\title{
Cold plasma-induced surface modification of heat-polymerized acrylic resin and prevention of early adherence of Candida albicans
}

\author{
Hong PAN ${ }^{1,2}$, Guomin WANG ${ }^{2}$, Jie PAN ${ }^{3}$, Guopin YE ${ }^{1,2}$, Ke SUN ${ }^{1,2}$, Jue ZHANG ${ }^{2}$ and Jing WANG ${ }^{1}$ \\ ${ }^{1}$ School of Stomatology, Lanzhou University, 199 West Dong-gang Road, Lanzhou 730000, China \\ ${ }^{2}$ Academy for Advanced Interdisciplinary Studies, Peking University, No.5 Yiheyuan Road, Beijing 100871, China \\ ${ }^{3}$ School of Stomatology, Peking University, 22\# Zhongguancun South Avenue, Beijing 100081, China \\ Corresponding author, Jing WANG; E-mail: Izukqwj@126.com
}

\begin{abstract}
Atmospheric-pressure cold plasma was applied to process the surface of heat-polymerized acrylic resin. Changes to the physical properties and early adherence of Candida albicans were investigated. Alternating current cold plasma with $\mathrm{Ar} / \mathrm{O}_{2}$ as working gas was used. Scanning electron microscopy (SEM) and X-ray photoelectron spectroscopy (XPS) were employed to study the possible mechanism. Experimental results showed that after plasma treatment, the contact angle of acrylic resin significantly decreased. There were no significant differences in roughness, flexural strength and elasticity modulus, but microhardness was significant improved in the treated group. More importantly, the early adherence of Candida albicans on the surface was reduced after plasma treatment. Cold plasma seemed to be a promising and convenient strategy of preventing the early adherence of Candida albicans on acrylic resins, which would greatly benefit potential dental applications.
\end{abstract}

Keywords: Heat-polymerized acrylic resin, Atmospheric-pressure cold plasma, Candida albicans, Contact angle, Early adherence

\section{INTRODUCTION}

Heat-polymerized acrylic resins are commonly used in prosthodontics, particularly in complete denture bases and partial denture bases due to their esthetically acceptable color and availability at low cost. However, there is a high incidence of denture-induced stomatitis in denture wearers ${ }^{1}$. Many studies have singled out Candida albicans as a potential causative agent in denture stomatitis ${ }^{2}$.

Several factors contribute to the development of Candida albicans: age of denture, salivary flow, and denture base material. As the adherence of Candida albicans to denture surfaces is now recognized as an important phase in its colonization and pathogenesis, inhibiting the early adherence process would be a significant measure in the prevention of stomatitis ${ }^{3)}$. The adherence of Candida albicans is influenced by many factors, such as surface roughness, salivary pellicle, surface free energy, and the type of denture base material ${ }^{4-77}$.

Some researchers found that an increase in surface roughness promoted fungal adhesion ${ }^{5,6,8}$. On the other hand, Hahnel et al. stated that there was no linear relationship between surface roughness and Candida albicans adherence ${ }^{9}$. According to previous studies, the adherence of Candida albicans to biomaterial surfaces could be affected by their relative hydrophobicity. Klotz et al. found a nearly linear relationship between the number of Candida albicans adhering per unit area and the hydrophobicity of polymers ${ }^{7}$. It was also reported that superhydrophilic surfaces prevented microbial

Color figures can be viewed in the online issue, which is available at J-STAGE.

Received Feb 4, 2015: Accepted Apr 16, 2015

doi:10.4012/dmj.2015-035 JOI JST.JSTAGE/dmj/2015-035 adherence ${ }^{10)}$ and that improved surface wettability increased the retention power of denture bases ${ }^{11,12)}$.

Atmospheric-pressure cold plasma - a complex mixture composed of ions, energetic free radicals, electrons, atoms, and molecules generated by gas discharge - has attracted much interest in biomedicine because of its potential applicability in bacterial inactivation $^{13,14)}$, tooth whitening ${ }^{15,16)}$, blood coagulation ${ }^{17)}$, and cancer therapy ${ }^{18)}$. In recent years, researchers reported that plasma could be used as an economical and effective means to modify dental materials' surfaces ${ }^{19-23)}$. Previous researches confirmed that after heat-cured acrylic resin was treated with cold plasma, it increased the shear bond strength between heat-cured acrylic resin and self-curing acrylic resin ${ }^{21}$. Nurhaerani et al. found that $\mathrm{CF}_{4}$ plasma was useful in inhibiting Streptococcus mutans adhesion on stainless steel surface ${ }^{22)}$. Zamperini et al. confirmed that $\mathrm{ArO}_{2} / 70 \mathrm{~W}$ and $\mathrm{ArSF}_{6} / 70 \mathrm{~W}$ plasma treatment groups showed significantly reduced Candida albicans biofilm adhesion than the control group after plasma treatment of heat-curing acrylic resin samples ${ }^{23)}$. However, the early adherence of Candida albicans on plasma-treated, heat-polymerized acrylic resins is rarely investigated.

The purpose of this study was to evaluate the effects of cold plasma treatment on the physical properties of heat-polymerized acrylic resin and early Candida albicans adhesion.

\section{MATERIALS AND METHODS}

\section{Specimen preparation}

Two types of specimens were prepared from heatpolymerized acrylic resin according to manufacturer's 
instructions (Vertex Rapid Simplified, Vertex-Dental Zeist, The Netherlands). Specimens A (d=12 mm, h=1 $\mathrm{mm} ; n=36$ ) were used for fungal adherence assessment and contact angle measurement. Half of specimens A were used for water contact angle measurement, and the other half for early adherence of Candida albicans. They were polished with 600-grit silicon carbide ( $\mathrm{SiC}$ ) paper to ensure the same surface roughness prior to further treatment.

Specimens B $(64 \times 10 \times 3.3 \mathrm{~mm} ; n=36)$ were used for the measurements of microhardness, surface roughness, flexural strength, and modulus of elasticity. They were progressively polished using waterproof $\mathrm{SiC}$ abrasive papers (Nos. 200, 400, 600, 800, 1200, 1500, and 2000).

For all specimens, half were non-treated as controls while the remaining specimens were treated with cold plasma. Each specimen was conditioned in distilled water at $37^{\circ} \mathrm{C}$ for $48 \mathrm{~h}$ to release residual monomers before the experiments were carried out.

\section{Cold plasma treatment}

A single-electrode, non-thermal, atmospheric-pressure plasma jet was used to treat the acrylic resin specimens. Figure 1a shows a heat-polymerized acrylic resin specimen being treated by plasma, and Fig. $1 \mathrm{~b}$ is a schematic diagram of the experimental setup.

The cold plasma jet device consisted of a Teflon tube (Daxiang, Beijing, China), a 1-M $\Omega$ resistor, and an outer copper foil that surrounded the Teflon tube. The outer copper foil, which served as a single electrode, was connected to a $10-\mathrm{kHz}$ sinusoidal high-voltage source (CTP-2000K, Suman, Nanjing, China) with an 18-kV peak-to-peak voltage. The Teflon tube had outer and inner diameters of $10 \mathrm{~mm}$ and $8 \mathrm{~mm}$ respectively. Premixed argon and oxygen (98\% $\mathrm{Ar}$ and 2\% $\mathrm{O}_{2}$ per volume) was used as the working gas and passed through the Teflon tube at a flow rate of $300 \mathrm{~L} / \mathrm{h}$. Plasma was generated inside the Teflon tube near the powered outer electrode, and then propagated to generate a continuous plasma jet up to $5 \mathrm{~cm}$ outside the Teflon tube in the surrounding air of atmospheric pressure. Distance between the tip of plasma jet and the specimen was approximately $10 \mathrm{~mm}$. Gas temperature near the specimen ranged between $34^{\circ} \mathrm{C}$ and $38^{\circ} \mathrm{C}$.

According to the different specimen sizes, specimens A were treated for $90 \mathrm{~s}$ by plasma, while specimens B were evenly treated for a total of $8.5 \mathrm{~min}$.

\section{Water contact angle measurement}

Surface wettability of specimens A was evaluated by measuring their water contact angles. An automated goniometer system (OCA 15 plus, Dataphysics Instruments, Filderstadt, Germany) equipped with SCA 20 software was used to analyze and calculate specific contact angles. Ultrapure water was used as test liquid. Image of water droplet in contact with specimen surface was immediately taken. Assessment of each droplet (2.0 $\mu \mathrm{L}$ ) on specimen surface comprised two measurements: right and left contact angles. Contact angles were measured before and after plasma treatment.
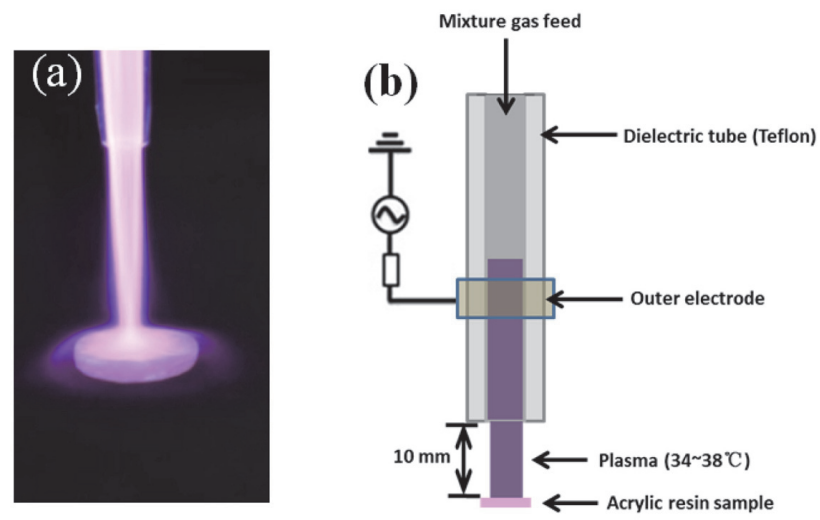

Fig. 1 (a) Heat-polymerized acrylic resin specimen being treated by non-thermal atmospheric-pressure plasma jet; (b) Schematic diagram of experimental setup.

\section{Preconditioning with saliva}

Non-stimulated whole human saliva was collected from two healthy adult volunteers. Saliva was centrifuged at $5,000 \mathrm{~g}$ for $10 \mathrm{~min}^{24)}$. Saliva supernatant was prepared at $50 \%$ ( $\mathrm{vol} / \mathrm{vol})$ in sterile phosphate-buffered saline (PBS), then immediately frozen and stored at $-70^{\circ} \mathrm{C}$. Before the experiments were carried out, saliva was carefully defrosted and sterilized using single-use filter units $(0.22 \mu \mathrm{m})$. Treatment group $(n=9)$ was incubated with saliva immediately after plasma treatment, while the control group $(n=9)$ was directly incubated with saliva. Specimens were incubated with $1 \mathrm{~mL}$ of prepared saliva at room temperature for $30 \mathrm{~min}$ to form an acquired pellicle.

\section{Candida albicans adhesion to specimen surface}

Microorganism used was Candida albicans ATCC 10231. To prepare the yeast inoculum, Candida albicans was seeded in an agar (SAD) culture medium (1\% yeast extract, $1 \%$ peptone, $2 \%$ dextrose, $2 \%$ agar) and incubated for $48 \mathrm{~h}$ at $37^{\circ} \mathrm{C}$. One loopful of this young culture was transferred to $30 \mathrm{~mL}$ of YPD liquid medium (1\% yeast extract, $1 \%$ peptone, $2 \%$ dextrose) and incubated at $37^{\circ} \mathrm{C}$ for $10 \mathrm{~h}$ in an orbital shaker incubator at $100 \mathrm{rpm}$. Candida suspensions were spectrophotometrically standardized to a concentration of $1 \times 10^{7} \mathrm{CFU} / \mathrm{mL}$. After incubation, the cells were twice washed with sterile PBS solution $(\mathrm{pH}=7.2)$ by agitation and centrifugation at $3,000 \mathrm{~g}$ for $5 \mathrm{~min}$.

Then, $1.5 \mathrm{~mL}$ of the standardized fungal cell suspension was transferred to each well of a 24-well microplate containing specimens A incubated with saliva (treatment group and control group). Cells were allowed to adhere on specimen surfaces for $90 \mathrm{~min}$ at $37^{\circ} \mathrm{C}$ at $100 \mathrm{rpm}$. Thereafter, specimens were washed with $2 \mathrm{~mL}$ of PBS for $1 \mathrm{~min}$ to remove non-adherent cells. The amount of Candida albicans cells adhering to acrylic specimen surfaces was evaluated by colony- 
forming unit (CFU) assay. After non-adherent cells were removed by washing, specimens were transferred to $15-\mathrm{mL}$ centrifuge tubes containing $10 \mathrm{~mL}$ of PBS. Centrifuge tubes were shaken for $2 \mathrm{~min}$, and gradient dilution method was used to count the CFUs. All experiments were performed in triplicate on three different occasions.

\section{Physical properties measurements}

1. Surface roughness measurement

Peak-to-valley surface roughness $(\mathrm{Ra})$ was measured before and after each treatment at five randomly selected sites of each specimen using a profilometer (SJ-400, Mitutoyo, Kanagawa, Japan). Average surface roughness (Ra) of each specimen was determined with a transverse length of $0.8 \mathrm{~mm}$. Travelling speed of probe was $0.5 \mathrm{~mm} / \mathrm{s}$. Mean Ra values $(\mu \mathrm{m})$ were calculated. All measurements were made by the same operator.

\section{Microhardness measurement}

Microhardness measurement was carried out using a Vicker's microhardness tester (HMV-2T, Shimadzu, Tokyo, Japan) under a load of $100 \mathrm{~g}$ for $30 \mathrm{~s}$. Five indentations were made at different sites on each specimen, and the mean values of individual specimens were obtained.

3. Flexural strength and elastic modulus measurements Specimens were subject to a three-point bending test using an electronic universal testing machine (Model 3367, Instron, Canton, MA, USA). Crosshead speed was $5.00 \mathrm{~mm} / \mathrm{min}$, and distance between the specimen supports was $50.00 \mathrm{~mm}$. Flexural strength (S) and elastic modulus (E) were calculated using the following formulae:

$$
\mathrm{S}=3 \mathrm{LP} / 2 \mathrm{WH}^{2}
$$

$$
\mathrm{E}=\mathrm{PL}^{3} / 4 \mathrm{WH}^{3} \mathrm{~d}
$$

where $\mathrm{P}$ is fracture load, $\mathrm{L}$ is the distance between the supports $(50 \mathrm{~mm}), \mathrm{W}$ and $\mathrm{H}$ represent the width $(10 \mathrm{~mm})$ and thickness $(3.3 \mathrm{~mm})$ of specimen respectively, and $\mathrm{d}$ is the deflection corresponding to load $\mathrm{P}$.

\section{SEM analysis}

Surface morphology of acrylic resin specimens and the adhesion state of Candida albicans on the surface were evaluated using a scanning electron microscope (SEM, JSM-5600LV, JEOL, Tokyo, Japan). Specimens adhered with Candida albicans were fixed in $2.5 \%$ glutaraldehyde in $0.1 \mathrm{~mol} / \mathrm{L}$ sodium cacodylate $(\mathrm{pH}=7.4)$ for $48 \mathrm{~h}$ at $4^{\circ} \mathrm{C}$, and then sequentially dehydrated in ethanol at $30 \%, 50 \%, 70 \%, 90 \%$, and $100 \%$ for $10 \mathrm{~min}$ each. Mounted specimens were sputter-coated with goldpalladium and examined by SEM. Specimens without Candida albicans were directly sputter-coated with gold-palladium.

\section{XPS analysis}

To study the mechanisms that might improve hydrophilicity and hence reduce Candida albicans adherence, X-ray photoelectron spectroscopy (XPS) was applied to analyze the chemical modifications of specimen surfaces. Surface elemental composition was determined by XPS (AXIS Ultra, Kratos Analytical, Manchester, UK). All XPS spectra were calibrated using the $\mathrm{C} 1 \mathrm{~s}$ peak at $284.8 \mathrm{eV}$ to compensate for residual charging effects. Data of percent elemental composition, elemental ratios, and peak fitting parameters were calculated using the software that accompanied XPS as supplied by Kratos.

\section{Optical emission spectroscopy (OES) analysis}

A conventional fiber optics spectrometer (AvaSpec-2048-8, Avantes, Eerbeek, The Netherlands) was used to record emissions arising from the major excited plasma species in the $250-850 \mathrm{~nm}$ range. Distance between the exit nozzle of plasma device and the receive port was $5 \mathrm{~mm}$. Recorded spectra were transferred to a computer for further analysis.

\section{Statistical analysis}

Comparisons of mean contact angle, surface roughness, microhardness, flexural strength, elastic modulus, and Candida albicans adherence data were performed using paired-sample $t$-test with SPSS 18.0. Statistically significant differences were determined at a level of $p<0.05$.

\section{RESULTS}

\section{Water contact angle}

Water contact angle of heat-polymerized acrylic resin significantly decreased $(p<0.001)$ from $77.94^{\circ} \pm 3.22^{\circ}$ to $41.91^{\circ} \pm 3.02^{\circ}$ (Fig. 2), indicating that the surface became more hydrophilic after $\mathrm{Ar} / \mathrm{O}_{2}$ plasma treatment.

\section{Early adhesion of Candida albicans}

As shown in Fig. 3, there was a significant difference in the CFU values of Candida albicans at early adherence between the control group and treatment group $(p<0.001)$.

\section{Physical properties of acrylic resin}

After plasma treatment, the microhardness of acrylic resin significantly increased $(p<0.001)$. In contrast, there were no significant differences $(p>0.05)$ in surface roughness, flexural strength, and elastic modulus of acrylic resin between the control group and treatment group (Table 1).

\section{SEM}

Difference in surface morphology was slight after plasma treatment (Figs. 4a and 4b). However, 90-s treatment with $\mathrm{Ar} / \mathrm{O}_{2}$ plasma significantly reduced the number of Candida albicans adhering on the surface (Figs. 4c and 4d). 


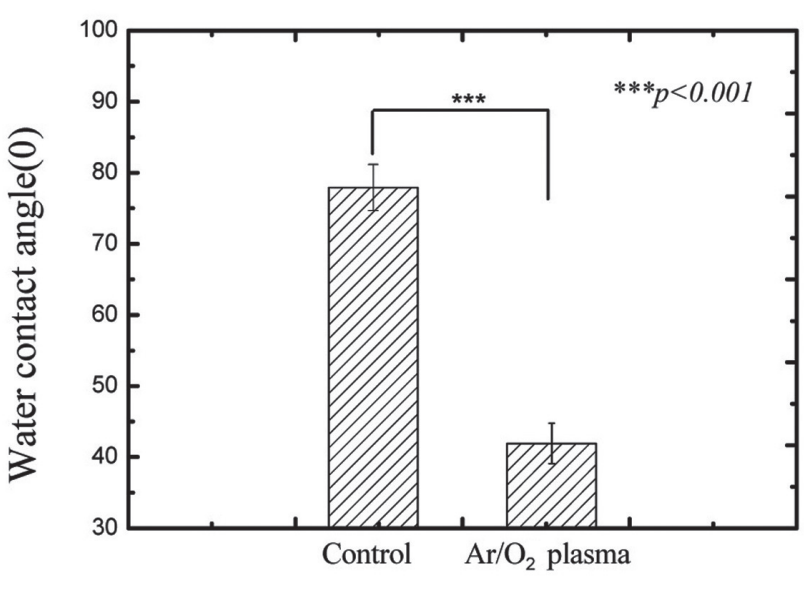

Treatment manners

Fig. 2 Changes in water contact angle before and after plasma treatment $(n=9)$.

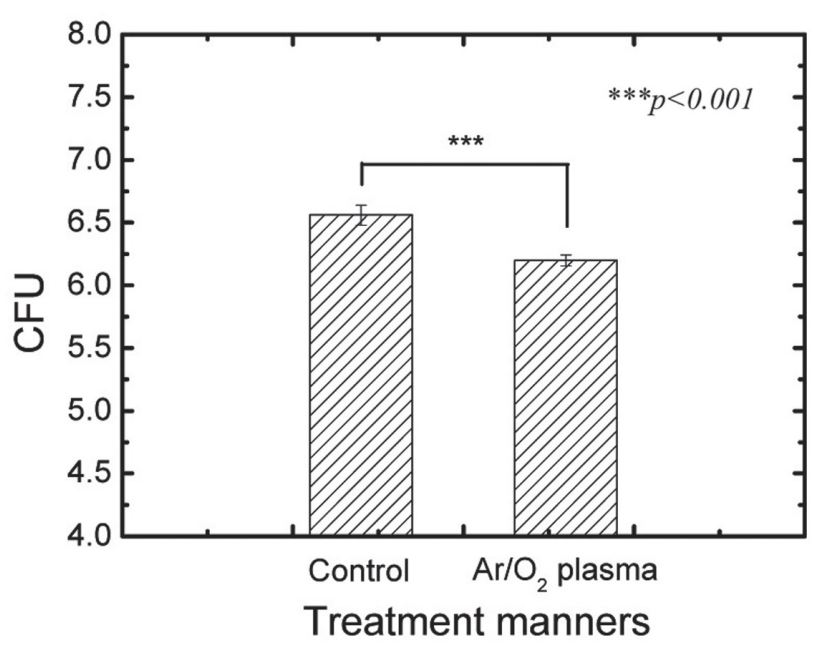

Fig. 3 Early adherence results of Candida albicans in the control group and after $\mathrm{Ar} / \mathrm{O}_{2}$ plasma treatment for $90 \mathrm{~s}$.

Table1 Changes in surface roughness, microhardness, flexural strength, and elastic modulus of heat-polymerized acrylic resin

\begin{tabular}{ccccc}
\hline Group & Roughness $(\mu \mathrm{m})$ & Microhardness $(\mathrm{Mpa})$ & Flexural Strength(Mpa) & Elasticity Modulus(Mpa) \\
\hline Control Group & $0.07 \pm 0.03$ & $19.67 \pm 0.51$ & $83.19 \pm 2.87$ & $2,756.20 \pm 129.25$ \\
Treatment Group & $0.07 \pm 0.03$ & $21.60 \pm 1.03^{* * *}$ & $80.62 \pm 6.99$ & $2,721.19 \pm 156.93$ \\
\hline
\end{tabular}

$* * * p<0.001, n=36$
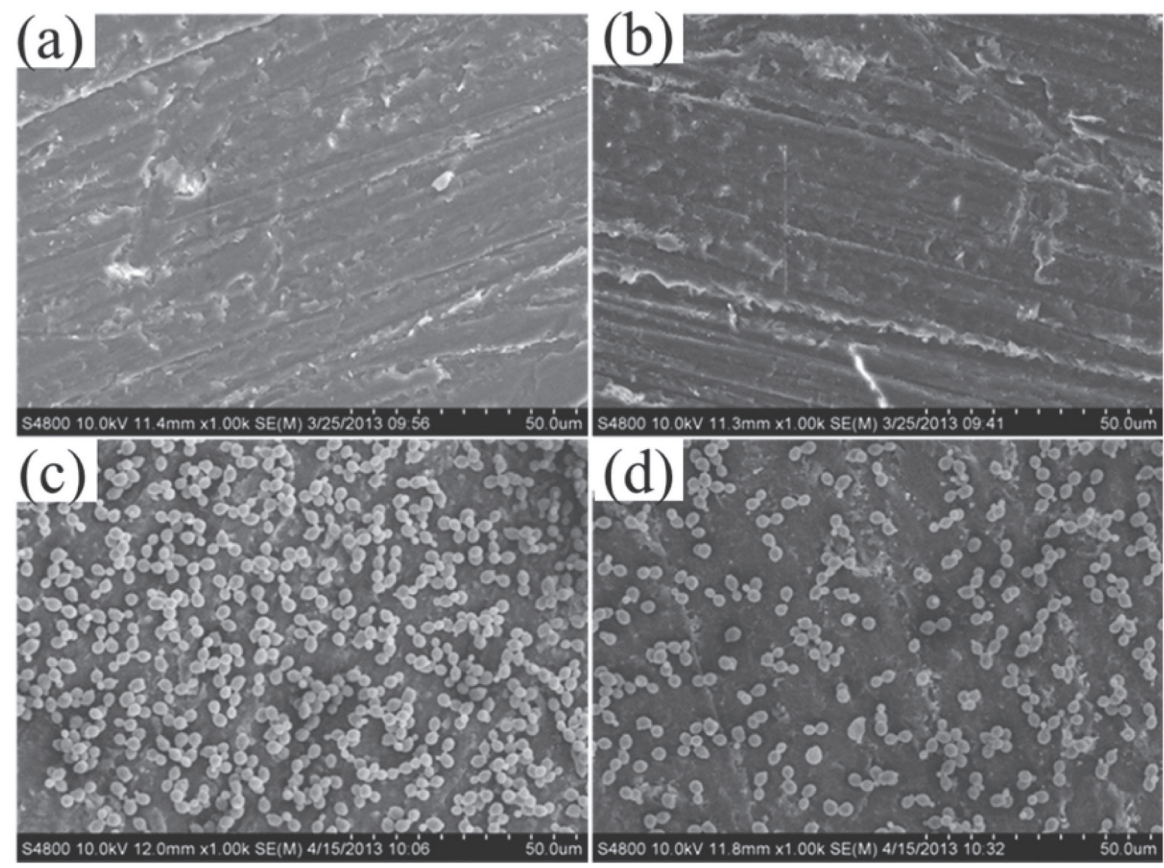

Fig. 4 Typical SEM results of: (a) control group without Candida albicans; (b) treatment group without Candida albicans; (c) Candida albicans adherence in control group; and (d) Candida albicans adherence in plasma-treated group. 


\section{$X P S$}

XPS scan spectra of both control and treatment groups are presented in Fig. 5. Fluorine molecules were detected on the treated specimen surface (Fig. 5b). As shown in Table 2, C/O ratio dramatically decreased from 4.32 to 2.56 .

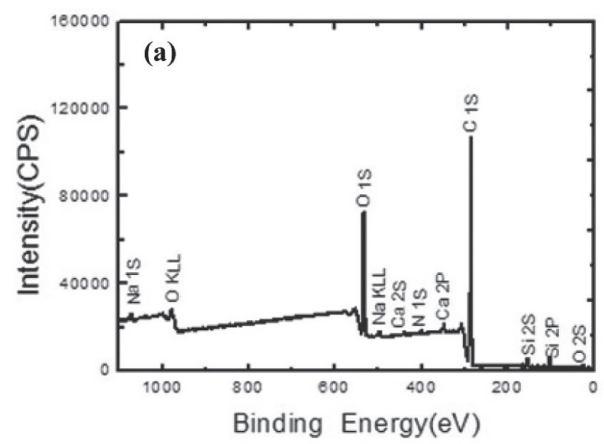

Results of XPS narrow scan spectra after carbon peak fitting are shown in Fig. 6. C 1s spectra of untreated specimens were resolved into three peaks (Fig. 6a). Peaks near 284.8, 286.1, and 288.5 eV were respectively assigned to the functional groups of $\mathrm{C}-\mathrm{C}-\mathrm{H}, \mathrm{O}-\mathrm{CH}_{3}$ and $\mathrm{O}-\mathrm{C}=\mathrm{O}^{25,26)}$ detected on the acrylic resin surface. After

Fig. 5 Typical XPS scan spectra of: (a) control group; and (b) treatment group.

Table 2 Elemental compositions (at.\%) of both control and treatment groups as determined by XPS

\begin{tabular}{ccccc}
\hline Group & C (at\%) & O (at\%) & F (at\%) & C/O proportion \\
\hline Control group & 81.19 & 18.81 & - & 4.32 \\
Treatment group & 70.53 & 27.57 & 1.90 & 2.56 \\
\hline
\end{tabular}
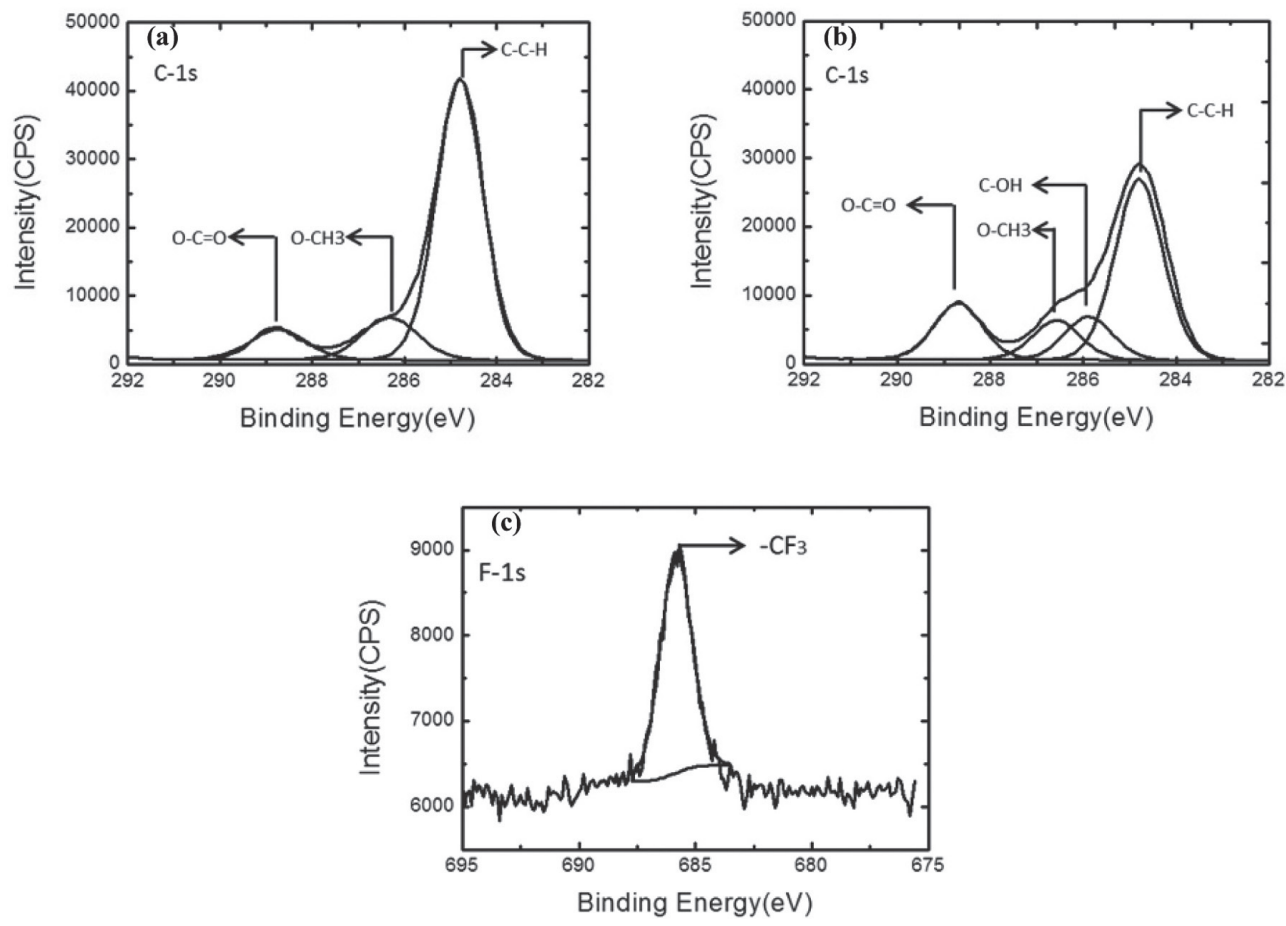

Fig. 6 (a) Carbon peak fitting of the XPS narrow scan spectra of control group; (b) Carbon peak fitting of the XPS narrow scan spectra of $\mathrm{Ar} / \mathrm{O}_{2}$ plasma treatment group; and (c) Fluorine peak fitting of XPS narrow scan spectra after $\mathrm{Ar} / \mathrm{O}_{2}$ plasma treatment. 


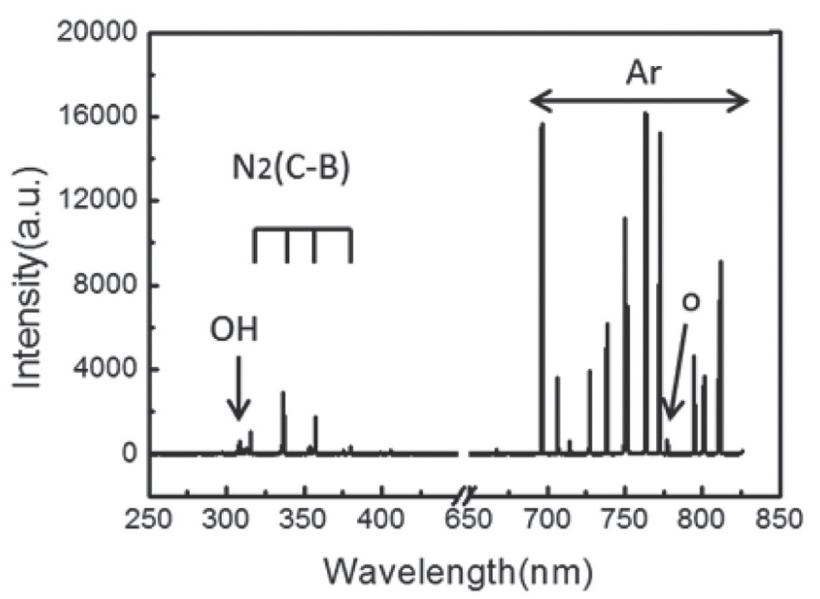

Fig. 7 Optical emission spectroscopy (OES) spectrum of $\mathrm{Ar} / \mathrm{O}_{2}$ plasma jet.

plasma treatment, the structures of $\mathrm{C}$ 1s spectra were markedly affected (Fig. 6b). Intensity of C 1s spectra around $286.5 \mathrm{eV}$ increased when compared with untreated acrylic resin, probably caused by the presence of a new functional group $\mathrm{C}-\mathrm{OH}^{26,27)}$. Fluorine peak fitting of XPS narrow scan spectra (Fig. 6c) revealed that a peak near $685.8 \mathrm{eV}$ was formed on the surface, which was assigned to the functional group $-\mathrm{CF}_{3}{ }^{28-30}$.

\section{OES}

Figure 7 presents the OES spectrum of $\mathrm{Ar} / \mathrm{O}_{2}$ plasma jet, indicating an abundance of active oxygen $(\mathrm{O})(777 \mathrm{~nm})$ and hydroxyl radicals $(\cdot \mathrm{OH})(306-309 \mathrm{~nm})$ present as the active components of plasma.

\section{DISCUSSION}

Heat-polymerized acrylic resins are a widely used biomaterial in dental clinics because they are biocompatible, hypoallergenic, and easily available at a low cost. To prevent denture stomatitis, efforts have been undertaken to inhibit the early adherence of Candida albicans. It was found that the more hydrophobic a surface was, the greater the Candida albicans adherence by area unit ${ }^{7}$. Puri et al. found that surface hydrophilicity was improved after phosphate was incorporated into an acrylic resin denture material by monomer substitution ${ }^{31)}$. However, it also resulted in dimensional changes and color instability ${ }^{31)}$. Recently, various coating approaches were developed and applied to denture base materials to increase surface hydrophilicity, with proven efficacy in reducing Candida albicans adherence ${ }^{24,27,32)}$. However, the coating layers were not stable.

Plasma treatments have been widely employed to modify the surface properties of polymers, such as biocompatibility, wettability, dyeability, and penetrability of materials ${ }^{33)}$. In this study, cold plasma was applied to modify the surface of acrylic resin to improve its hydrophilicity, thus reducing the early adherence of Candida albicans.

Water contact angle results in this study suggested that cold plasma could effectively improve surface hydrophilicity. This was caused by the cleavage of original functional groups and formation of new hydrophilic groups on the acrylic resin surface, as confirmed by XPS analysis. After cold plasma treatment, the mechanical properties of heat-polymerized acrylic resin, such as flexural strength and elastic modulus, were found to be stable.

Dental materials exposed to the oral environment are immediately covered with salivary films. In the present study, saliva was used to better simulate Candida albicans adherence. Recent reports stated that salivary films neither influenced Candida albicans adhesion nor significantly altered surface free energy and its polar and dispersive components ${ }^{23,24)}$. In this study, $\mathrm{Ar} / \mathrm{O}_{2}$ plasma treatment caused a significant decrease in contact angle and Candida albicans adhesion (Figs. 2 and 3). These results indicated that hydrophobic interaction was an important factor in Candida albicans adherence, which was in agreement with previous studies $^{7,27,32)}$. Improved hydrophilicity could also enhance the retention of denture bases because the presence of more liquid molecules and higher surface tension help to form the seal that can keep air away from the denture base and tissue surfaces.

Surface reactions caused by cold plasma treatment are determined by many factors, including substrate properties, plasma generator, working gas used, reaction conditions (power, pressure, operating distance, and exposure time), and reactor geometry. In this study, XPS analysis was employed to investigate the valence band structures and chemical states of the surface before and after treatment. After plasma treatment, $\mathrm{C} / \mathrm{O}$ proportion was reduced and two new groups, $\mathrm{C}-\mathrm{OH}$ and $-\mathrm{CF}_{3}$, were detected. When high-energy particles and free radicals which existed in plasma impinged on the treated acrylic resin surface, some low-energy chemical bonds were easily broken. The chemical microenvironment of surface was thus changed, and formation of new chemical bonds was induced. As for the decrease of $\mathrm{C} / \mathrm{O}$ ratio after plasma treatment, we surmised that the resin surface was first oxidized by plasma. The C-C chemical bond ruptured, and active ingredient $\cdot \mathrm{OH}$ (according to OES spectrum in Fig. 7) from plasma was grafted on the $\mathrm{C}$-bond, leading to the formation of new $\mathrm{C}$-OH bond. Numerous researchers have realized that the existence of $\mathrm{C}-\mathrm{OH}$ bond is beneficial to hydrophilicity ${ }^{34,35)}$. Since hydrophobic interaction plays an important role to the adhesion of Candida albicans to denture base materials, the new $\mathrm{C}-\mathrm{OH}$ bond is a new positive alternative to reducing denture stomatitis.

Fluorine (F) molecules were also detected on the treated acrylic resin surface, probably due to the plasma generating device - that is, the Teflon tube. As a polar group, $-\mathrm{CF}_{3}$ can reduce the adhesion of Candida albicans $^{23)}$. Based on the XPS results, we surmised that after $\mathrm{F}$ ion broke some pendant groups, it bound itself 
to unbound carbon atoms, leading to the formation of new C-F bond. This speculation needs further experiments to verify.

Microhardness can be defined as a material's resistance to indenter penetration. It is calculated by dividing the test force by surface area of contact, incorporating the plastic component of displacement. Results in this study showed that plasma treatment significantly increased surface microhardness, which could be attributed to the plasma-induced crosslinking phenomenon ${ }^{36-40)}$. Thus, plasma would also be helpful in enhancing the etch resistance of denture bases ${ }^{41}$. As for the other physical properties of heat-polymerized acrylic resin, such as surface roughness, flexural strength and elasticity modulus, they were not affected by plasma treatment. This is a big advantage compared with other surface modification methods.

The limitation of this study was that all data of the treatment group were measured immediately after plasma treatment. Further research is needed to investigate the long-term effects. Experiments on the detailed mechanism will also be carried out.

\section{CONCLUSION}

$\mathrm{Ar} / \mathrm{O}_{2}$ plasma treatment seemed to be a promising technique to improve the surface wettability of denture base materials without degrading the material's physical properties, and hence significantly reduce early Candida albicans adherence. It would be a valuable means for the surface modification of acrylic resins and prevention of denture stomatitis.

\section{REFERENCES}

1) Arendorf T, Walker D. Denture stomatitis: a review. J Oral Rehabil 1987; 14: 217-227.

2) Ramage G, Tomsett K, Wickes BL, López-Ribot JL, Redding SW. Denture stomatitis: a role for Candida biofilms. Oral Surg Oral Med Oral Pathol Oral Radiol Endod 2004; 98: 5359.

3) Yoshijima Y, Murakami K, Kayama S, Liu D, Hirota K, Ichikawa T, Miyake Y. Effect of substrate surface hydrophobicity on the adherence of yeast and hyphal Candida. Mycoses 2010; 53: 221-226.

4) Yamauchi M, Yamamoto K, Wakabayashi M, Kawano J. In vitro adherence of microorganisms to denture base resin with different surface texture. Dent Mater J 1990; 9: 19-24.

5) Verran J, Maryan CJ. Retention of Candida albicans on acrylic resin and silicone of different surface topography. J Prosthet Dent 1997; 77: 535-539.

6) Radford DR, Sweet SP, Challacombe SJ, Walter JD. Adherence of Candida albicans to denture-base materials with different surface finishes. J Dent 1998; 26: 577-583.

7) Klotz SA, Drutz DJ, Zajic JE. Factors governing adherence of Candida species to plastic surfaces. Infect Immun 1985; 50: 97-101.

8) Pereira-Cenci T, Pereira T, Cury A, Cenci M, RodriguesGarcia R. In vitro Candida colonization on acrylic resins and denture liners: influence of surface free energy, roughness, saliva, and adhering bacteria. Int J Prosthodont 2007; 20: 308-310.

9) Hahnel S, Rosentritt M, Handel G, Bürgers R. In vitro evaluation of artificial ageing on surface properties and early
Candida albicans adhesion to prosthetic resins. J Mater Sci Mater Med 2009; 20: 249-255.

10) Hirota K, Murakami K, Nemoto K, Miyake Y. Coating of a surface with 2-methacryloyloxyethyl phosphorylcholine (MPC) co-polymer significantly reduces retention of human pathogenic microorganisms. FEMS Microbiol Lett 2005; 248: $37-45$.

11) Sipahi C, Anil N, Bayramli E. The effect of acquired salivary pellicle on the surface free energy and wettability of different denture base materials. J Dent 2001; 29: 197-204.

12) Monsenego P, Baszkin A, de Lourdes Costa M, Lejoyeux J. Complete denture retention. Part II: Wettability studies on various acrylic resin denture base materials. J Prosthet Dent 1989; 62: 308-312.

13) Feng H, Sun P, Chai Y, Tong G, Zhang J, Zhu W, Fang J. The interaction of a direct-current cold atmospheric-pressure air plasma with bacteria. IEEE Trans Plasma Sci 2009; 37: 121127.

14) Lu X, Cao Y, Yang P, Xiong Q, Xiong Z, Xian Y, Pan Y. An $\mathrm{RC}$ plasma device for sterilization of root canal of teeth. IEEE Trans Plasma Sci 2009; 37: 668-673.

15) Pan J, Sun P, Tian Y, Zhou H, Wu H, Bai N, Liu F, Zhu W, Zhang J , Becker KH, Fang J. A novel method of tooth whitening using cold plasma microjet driven by direct current in atmospheric-pressure air. IEEE Trans Plasma Sci 2010; 38: 3143-3151.

16) Lee HW, Kim GJ, Kim JM, Park JK, Lee JK, Kim GC. Tooth bleaching with nonthermal atmospheric pressure plasma. J Endod 2009; 35: 587-591.

17) Fridman G, Peddinghaus M, Balasubramanian M, Ayan H, Fridman A, Gutsol A, Brooks AD. Blood coagulation and living tissue sterilization by floating-electrode dielectric barrier discharge in air. Plasma Chem Plasma Process 2006; 26: 425-442.

18) Fridman G, Shereshevsky A, Jost MM, Brooks AD, Fridman A, Gutsol A, VasiletsV, Friedman G. Floating electrode dielectric barrier discharge plasma in air promoting apoptotic behavior in melanoma skin cancer cell lines. Plasma Chem Plasma Process 2007; 27: 163-176.

19) Duske K, Koban I, Kindel E, Schröder K, Nebe B, Holtfreter B, Jablonowski L, Weltmann KD, Kocher T. Atmospheric plasma enhances wettability and cell spreading on dental implant metals. J Clin Periodontol 2012; 39: 400-407.

20) Ritts AC, Li H, Yu Q, Xu C, Yao X, Hong L, Wang Y. Dentin surface treatment using a non-thermal argon plasma brush for interfacial bonding improvement in composite restoration. Eur J Oral Sci 2010; 118: 510-516.

21) Nishigawa G, Maruo Y, Oka M, Oki K, Minagi S, Okamoto M. Plasma treatment increased shear bond strength between heat cured acrylic resin and self-curing acrylic resin. J Oral Rehabil 2003; 30: 1081-1084.

22) Nurhaerani, Arita K, Shinonaga Y, Nishino M. Plasma-based fluorine ion implantation into dental materials for inhibition of bacterial adhesion. Dent Mater J 2006; 25: 684-692.

23) Zamperini CA, Machado AL, Vergani CE, Pavarina AC, Giampaolo ET, da Cruz NC. Adherence in vitro of Candida albicans to plasma treated acrylic resin. Effect of plasma parameters, surface roughness and salivary pellicle. Arch Oral Biol 2010; 55: 763-770.

24) Lazarin AA, Machado AL, Zamperini CA, Wady AF, Spolidorio DM, Vergani CE. Effect of experimental photopolymerized coatings on the hydrophobicity of a denture base acrylic resin and on Candida albicans adhesion. Arch Oral Biol 2013; 58: $1-9$.

25) Dai W, Ko TJ, Oh KH, Lee KR, Moon MW. Ion-beam induced surface roughening of poly-(methyl methacrylate) (PMMA) tuned by a mixture of Ar and $\mathrm{O} 2$ ions. Plasma Process Polym 2012; 9: 975-983

26) Rosencrance SW, Way WK, Winograd N, Shirley DA. 
Polymethylmethacrylate by XPS. Surf Sci Spectra 1993; 2: 71-75.

27) Azuma A, Akiba N, Minakuchi S. Hydrophilic surface modification of acrylic denture base material by silica coating and its influence on Candida albicans adherence. J Med Dent Sci 2012; 59: 1-7.

28) Lee JM, Kim SJ, Kim JW, Kang PH, Nho YC, Lee YS. A high resolution XPS study of sidewall functionalized MWCNTs by fluorination. J Ind Eng Chem 2009; 15: 66-71.

29) Palchan I, Crespin M, Estrade-Szwarckopf H, Rousseau B. Graphite fluorides: an XPS study of a new type of C-F bonding. Chem Phys Lett 1989; 157: 321-327.

30) Liu ZM, Zhou XL, Kiss J, White J. Interaction of CF3I with Pt(111). Surf Sci 1993; 286: 233-245.

31) Puri G, Berzins DW, Dhuru VB, Raj PA, Rambhia SK, Dhir G, Dentino AR. Effect of phosphate group addition on the properties of denture base resins. J Prosthet Dent 2008; 100: 302-308.

32) Arai T, Ueda T, Sugiyama T, Sakurai K. Inhibiting microbial adhesion to denture base acrylic resin by titanium dioxide coating. J Oral Rehabil 2009; 36: 902-908.

33) Chu PK, Chen JY, Wang LP, Huang N. Plasma-surface modification of biomaterials. Mat Sci Eng R 2002; 36: 143206.

34) Dong X, Shen W, Gu J, Xiong L, Zhu Y, Li H, Shi J. A structure of $\mathrm{MnO}_{2}$ embedded in CMK-3 framework developed by a redox method. Micropor Mesopor Mat 2006; 91: 120-127.

35) Kawashita M, Shimatani H, Itoh S, Araki R, Takaoka GH. Apatite deposition on polymer substrates irradiated by oxygen cluster ion beams. J Ceram Soc Jpn 2006, 114: 77-81.

36) Singh N, Pelagade S, Rane R, Mukherjee S, Deshpande U, Ganeshan V, Shripathi T. Influence of argon plasma treatment on polyethersulphone surface. Pramana 2013; 80: 133-141.

37) Lee EH, Rao GR, Mansur LK. LET effect on cross-linking and scission mechanisms of PMMA during irradiation. Radiat Phys Chem 1999; 55: 293-305.

38) Singh NL, Qureshi A, Shah N, Rakshit AK, Mukherjee S, Tripathi A, Avasthi DK. Surface modification of polyethylene terephthalate by plasma treatment. Radiat Meas 2005; 40: 746-749.

39) Lee EH, Rao GR, Mansur LK. Hardness enhancement and crosslinking mechanisms in polystyrene irradiated with high energy ion-beams. Mater Sci Forum 1997; 135-146.

40) Qureshi A, Shah S, Pelagade S, Singh NL, Mukherjee S, Tripathi A, Despande UP, Shripathi T. Surface modification of polycarbonate by plasma treatment. J Phys: Conference Series: IOP Publishing 2010: 012108.

41) Wong S, Ross M. Enhancement of photoresist plasma etch resistance via electron beam surface cure. US Patent 6,358,670 [P]. 2002-3-19. 